\title{
Association between blood glucose level derived using the oral glucose tolerance test and glycated hemoglobin level
}

\author{
Hyoung Joo Kim ${ }^{1}$, Young Geon Kim ${ }^{1}$, Jin Soo Park ${ }^{1}$, Young Hwan Ahn ${ }^{1}$, Kyoung Hwa $\mathrm{Ha}^{2,3}$, \\ and Dae Jung $\mathrm{Kim}^{2,3}$
}

Departments of ${ }^{1}$ Internal Medicine and ${ }^{2}$ Endocrinology and Metabolism, ${ }^{3}$ Cardiovascular and Metabolic Disease Etiology Research Center, Ajou University School of Medicine, Suwon, Korea

Received: March 18, 2015

Revised : June 15, 2015

Accepted: June 15, 2015

\section{Correspondence to}

Dae Jung Kim, M.D.

Department of Endocrinology and Metabolism, Ajou University

School of Medicine, 164 World

cup-ro, Yeongtong-gu, Suwon

16499 , Korea

Tel: +82-31-219-5128

Fax: +82-31-219-4497

E-mail: djkim@ajou.ac.kr
Background/Aims: Glycated hemoglobin (HbAic) is widely used as a marker of glycemic control. Translation of the HbAic level to an average blood glucose level is useful because the latter figure is easily understood by patients. We studied the association between blood glucose levels revealed by the oral glucose tolerance test (OGTT) and HbAic levels in a Korean population.

Methods: A total of 1,000 subjects aged 30 to 64 years from the Cardiovascular and Metabolic Diseases Etiology Research Center cohort were included. Fasting glucose levels, post-load glucose levels at 30, 60, and 120 minutes into the OGTT, and $\mathrm{HbAic} \mathrm{levels} \mathrm{were} \mathrm{measured.}$

Results: Linear regression of HbAic with mean blood glucose levels derived using the OGTT revealed a significant correlation between these measures (predicted mean glucose $\left.[\mathrm{mg} / \mathrm{dL}]=49.4 \times \mathrm{HbAlc}[\%]-149.6 ; R^{2}=0.54, p<0.001\right)$. Our linear regression equation was quite different from that of the Alc-Derived Average Glucose (ADAG) study and Diabetes Control and Complications Trial (DCCT) cohort. Conclusions: Discrepancies between our results and those of the ADAG study and DCCT cohort may be attributable to differences in the test methods used and the extent of insulin secretion. More studies are needed to evaluate the association between HbAic and self monitoring blood glucose levels.

Keywords: Diabetes mellitus; Hemoglobin A, glycosylated; Oral glucose tolerance test; Mean blood glucose level

\section{INTRODUCTION}

Diabetes is a very prevalent chronic disease. In 2011, approximately four million Korean adults had been diagnosed with diabetes, representing $12.4 \%$ of the overall adult population over 30 years of age [1]. Most individuals with type 2 diabetes have pre-diabetes for several years prior to a diagnosis of diabetes, by which point complications may already have progressed [2].

In the mid-1970s, glycated hemoglobin (HbAic) was identified as a marker of average glycemic control during the 2 to 3 months prior to measurement. As blood glucose levels vary widely during both fasting and postprandial periods, the $\mathrm{HbAlc}$ level is a more accurate indicator of long-term glycemic control. However, HbAic levels are of little diagnostic value because they are not standardized. In 2009, advances in test technology finally allowed an international expert committee to recommend inclusion of $\mathrm{HbAlc}$ level in the diagnostic criteria for diabetes [3]. In 2010, HbA1c thresholds of $\geq 6.5 \%$ for 
"diabetes" and 5.7\% to $6.4 \%$ for "pre-diabetes" were added to the American Diabetes Association (ADA) diagnostic guidelines [4].

Measurement of $\mathrm{HbA1c}$ level entails a one-time blood test that does not require prior fasting, and the test is familiar to most clinicians [5]. Many studies of the associations between $\mathrm{HbArc} \mathrm{levels} \mathrm{and} \mathrm{vascular} \mathrm{complications}$ have been reported. According to the Diabetes Control and Complications Trial (DCCT) and the UK Prospective Diabetes Study, effective management of HbAic level can reduce the risk of microvascular complications including retinopathy and nephropathy $[6,7]$. Control Group et al. [8] reported that strict control of the HbAic level reduced the risk of macrovascular complications.

Although the HbAic level is thus widely used as a clinical marker of diabetes, most patients do not understand its clinical implications. In a British study of 83 patients with diabetes, only $26.5 \%$ had accurate knowledge of what the HbArc level indicated. If patients lack such knowledge and appropriate medications and dietary interventions are not used in a timely manner, diabetes self-management may be ineffective, rendering glycemic control unsuccessful [9]. Thus, efforts have been made to translate $\mathrm{HbArc}$ values into blood glucose levels, with which most patients are familiar, potentially bridging the knowledge gap. In the Alc-Derived Average Glucose (ADAG) study by Nathan et al. [10], continuous glucose values and mean capillary glucose values (measured seven times daily) were obtained from patients with type 1, type 2 diabetes and healthy participants and were used to derive a novel equation yielding estimated average glucose (eAG) values from HbAic data. Despite the known association between $\mathrm{HbAic}$ and mean glucose levels, Makris and Spanou [11] analyzed several studies and found that the predictive intervals were too broad to allow the accuracy of various equations to be confirmed. Although many studies on the association between HbAic and average glucose level have been performed worldwide, no Korean study has yet been performed. Accordingly, the present study examined the association between HbArc level and mean blood glucose level from oral glucose tolerance test (OGTT) data in a community cohort.

\section{METHODS}

\section{Study design and participants}

The study design was a cross-sectional analysis of baseline data collected for an ongoing prospective cohort study. The Cardiovascular and Metabolic Diseases Etiology Research Center (CMERC) study was established to improve cardiovascular and metabolic disease predictive models, to discover new risk factors and biomarkers, to explore new preventative strategies, and to gather direct evidence relevant to prevention of cardiovascular and metabolic diseases since 2013. The CMERC is a multi-institutional, and it features two community-based cohorts and one hospital-based cohort. For the community cohorts, adults aged 30 to 64 years who voluntarily visited center and have lived in the study areas for a minimum of 8 months were/will be considered (the community-based cohort 1 set on in Seoul-si, Goyang-si, Gimpo-si, and Ganghwa-gun; the community-based cohort 2 set on in Suwon-si, Yongin-si, and Hwaseongsi). Of potential participants, those diagnosed with malignant tumors within the previous 2 years, those who have a history of myocardial infarction, stroke, or other cardiovascular disease, and those who are pregnant are excluded.

This analysis enrolled participants who completed baseline health examinations of community-based cohort (adults residing in Suwon, Yongin, and Hwasung) between December 2013 and October 2014. Among 1,001 participants (392 males and 609 females), we excluded one subject who failed to perform OGTT was excluded. Thus, a total of 1,000 subjects (391 males and 609 females) were included in the present study. Written informed consent was obtained from all participants, and the study was approved by the Ajou University Institutional Review Board (IRB No. AJIRB-BMR-SUR-13-272).

\section{Measurements}

All study participants underwent one-on-one interviews, and details about age, smoking status, alcohol use, previous diseases, and current medication status were recorded. To ensure that the survey was standardized, a manual was given to all interviewers, who also underwent a comprehensive training session. Those who conducted the survey had successfully completed training.

An automatic height-weight scale (BSM330, InBody 
Co. Ltd., Seoul, Korea) was used to measure height (cm) and weight $(\mathrm{kg})$ to a resolution of $0.1 \mathrm{~cm}$ and $0.1 \mathrm{~kg}$, respectively. The body mass index (BMI) was calculated using the formula weight/height ${ }^{2}\left(\mathrm{~kg} / \mathrm{m}^{2}\right)$. A measuring tape (Seca GmbH, Hamburg, Germany) was used for waist measurements; after identifying the last rib and hipbone via touch, the distance from the bottom edge of the last rib to the midpoint of the iliac crest on the mid-axillary plane was measured to $0.1 \mathrm{~cm}$ with the subject in an upright position.

To minimize interobserver and intraobserver variation, blood pressure was measured using an automated blood pressure monitor (HEM-708oIC, Omron Healthcare, Lake Forest, IL, USA). Prior to such measurement, a short survey information session was scheduled to allow each participant at least 10 minutes to relax in a sitting position. This was followed by an additional planned 5-minute relaxation period with the monitor in place prior to recording three blood pressure measurements. Measurements were taken at 2-minute intervals, with participants sitting comfortably and relaxed between readings. The last two of the three measurements were averaged.

Participants were required to fast for 8 hours prior to blood sampling. After blood sampling was done, the OGTT was performed to allow accurate diagnosis of diabetes. For this test, each participant was asked to drink a solution containing $75 \mathrm{~g}$ of glucose, after which blood samples were taken at 30,60, and 120 minutes for measurement of blood glucose levels. Participant's blood was collected from the brachial vein. The samples were properly processed, refrigerated at $2^{\circ} \mathrm{C}$ to $8^{\circ} \mathrm{C}$, and transported to the central laboratory (Seoul Clinical Laboratories, Seoul, Korea). Blood samples were analyzed within 24 hours of transportation. Additionally, total cholesterol, high density lipoprotein cholesterol (HDL-C), triglyceride, and HbAıc levels were measured. The serum glucose level of fasting and after glucose load were obtained using a colorimetric method, whereas the serum total cholesterol, HDL-C, and triglyceride values were determined via enzymatic methods using an autoanalyzer (ADVIA 1800 Auto Analyzer, Siemens Medical Solutions, Malvern, PA, USA). HbAic levels were determined via high-performance liquid chromatography with the aid of a Variant II Turbo analyzer (Bio-Rad, Hercules, CA, USA). The following ADA diabetes criteria were used in diagnosis: fasting serum glucose (FSG) level $\geq 126 \mathrm{mg} / \mathrm{dL}$, 2-hour OGTT glucose value $\geq 200 \mathrm{mg} /$ $\mathrm{dL}$, or an HbAic proportion $\geq 6.5 \%$. In this study, "mean blood glucose level" defined as average value of FSG and measured glucose during OGTT.

\section{Statistical analysis}

Between-gender differences were explored by calculating quantitative descriptive statistics. All data are presented as mean \pm standard deviation or median with interquartile range. To compare variables by diagnostic status, one-way analysis of variance was performed, with the significance level set at $p<0.05$. Mean blood glucose level associated with each $\mathrm{HbA1c}$ range were derived. To develop an equation by which HbA1c level predicted the mean glucose value, simple regression analysis was performed excluding HbAic values $\geq 8 \%$. SAS version 9.2 (SAS Institute Inc., Cary, NC, USA) was used in all analyses.

\section{RESULTS}

Table 1 shows the general characteristics of the study participants. The 1,000 participants included 391 males and 609 females. Of these, 48 males and 49 females had either been previously diagnosed or were newly diagnosed with diabetes, whereas 144 males and 188 females were diagnosed with pre-diabetes. Mean subject ages were $48.3 \pm 8.4$ years for males and $48.6 \pm 8.5$ years for females. All participants were divided into three groups by fasting glucose levels, 2-hour OGTT glucose level, and HbAic levels; these were labeled "normal," "pre-diabetic," and "diabetic." In females, significant amonggroup differences were evident in terms of systolic and diastolic blood pressure, BMI, waist circumference, total cholesterol, HDL-C, triglyceride, fasting glucose, 2-hour OGTT glucose, and HbAic levels. In males, significant differences were evident for all variables except total cholesterol (Table 1).

The HbA1c ranges were $5.4 \%$ to $12.5 \%$ in the diabetic group, $5.1 \%$ to $6.4 \%$ in the pre-diabetic group, and $4.4 \%$ to $5.6 \%$ in the normal group. The mean HbA1c values for both males and females in the normal group were $5.3 \%$. In the pre-diabetic group, the $\mathrm{HbA1c}$ values were $5.7 \%$ for males and $5.8 \%$ for females, and the HbAic val- 

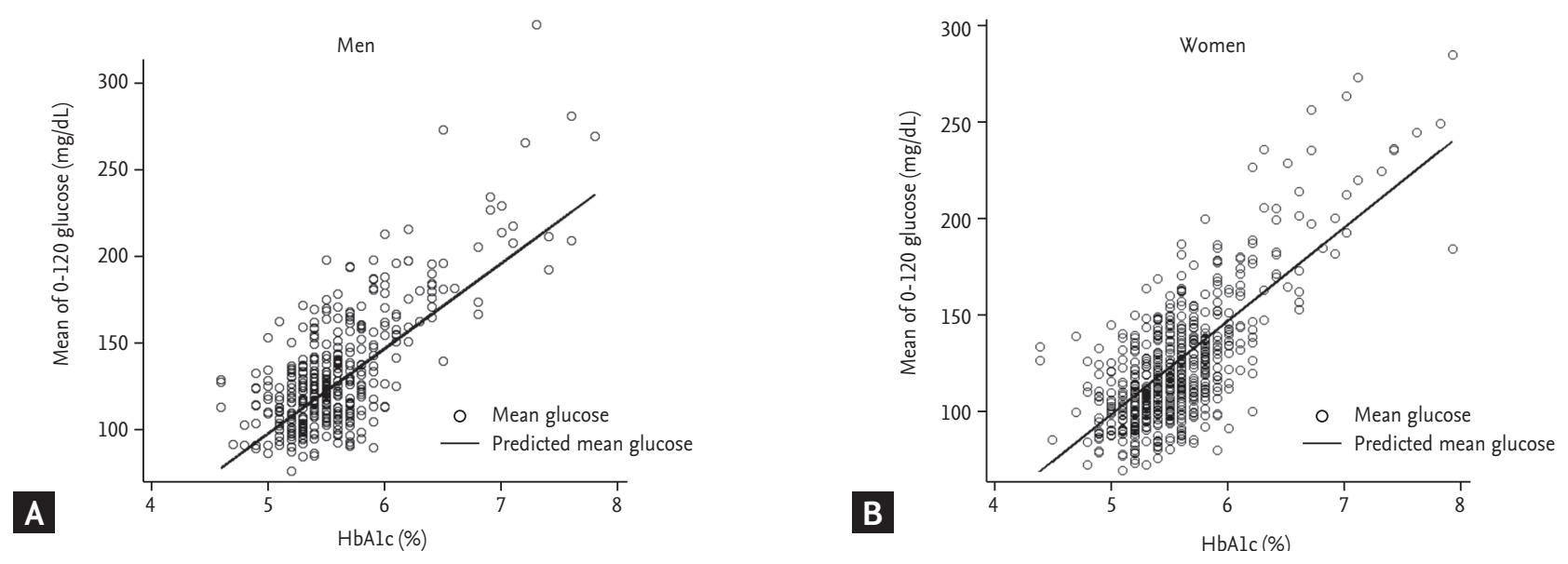

Figure 1. Scatter plots including regression lines of mean serum glucose levels relative to glycated hemoglobin (HbA1c) levels in (A) men and (B) women. Linear regression predicted mean glucose $(\mathrm{mg} / \mathrm{dL})=49.4 \times \mathrm{HbA1c}(\%)-149.6\left(R^{2}=0.54, p<0.001\right)$.

ues for both males and females in the diabetic group were $7.1 \%$ (data not shown).

Both fasting glucose and mean blood glucose level were analyzed in relation to the HbArc values. Seventeen patients had $\mathrm{HbAlc}$ values $\geq 8 \%$ of these, five had values $\geq 10 \%$. However, these patients were too few in number to justify reclassification within the range (Table 2). The mean blood glucose level increased as HbAic values rose. To explore the association between the mean blood glucose level and HbArc value, simple regression was performed, excluding participants with HbAlc value $\geq 8 \%$ (Fig. 1). The estimated linear regression equation is shown below: mean blood glucose level $(\mathrm{mg} / \mathrm{dL})=49.4 \times \mathrm{HbAlc}(\%)-149.6\left(R^{2}=0.54, p<0.001\right)$.

Because HbArc values are known to be low relative to the glucose levels in patients with anemia or cirrhosis or renal dysfunction, we also examined the estimation of mean blood glucose level after excluding 83 participants with anemia (hemoglobin, < $13 \mathrm{~g} / \mathrm{dL}$ for male; $<12$ $\mathrm{g} / \mathrm{dL}$ for female) or renal (glomerular filtration rate, $<30$ $\mathrm{mL} / \mathrm{min} / 1.73 \mathrm{~m}^{2}$ ) or hepatic dysfunction, and, estimated mean blood glucose level derived from same HbAic differs about $1 \mathrm{mg} / \mathrm{dL}$ (data not shown).

Table 3 shows the estimated mean blood glucose levels by $\mathrm{HbA1c}$ levels. After excluding $\mathrm{HbA1c}$ values of $5 \%$, the equation of the present study yielded a higher mean glucose level than was found in the ADA or ADAG study. In the ADAG study, a $1 \%$ increase in $\mathrm{HbAlc}$ level was associated with a $30 \mathrm{mg} / \mathrm{dL}$ increase in glucose level. However, the equivalent figure in the present study was
$50 \mathrm{mg} / \mathrm{dL}$.

\section{DISCUSSION}

As far as we know, this is the first study in Korea trying to analyze the association between $\mathrm{HbAlc}$ and mean blood glucose level during OGTT. We found a positive correlation between $\mathrm{HbA1c}$ and mean blood glucose level. High post-prandial or post-load glucose levels are attributable to reduced insulin secretion rather than to insulin-resistance [12]. The HbA1c level is more significantly affected by the postprandial blood glucose level than by the fasting glucose level, especially in subjects with HbA1c levels < 7.3\% [13]. As most study participants were non-diabetic or were diabetic subjects exhibiting good glycemic control (a mean HbA1c level of 7.1\%), compromised insulin secretion may have caused the observed high glucose level and increased the $\mathrm{HbA1c}$, as evident in the OGTT.

In the present study, the mean difference in glucose level $(50 \mathrm{mg} / \mathrm{dL})$ was much greater than that reported by the ADAG study ( $30 \mathrm{mg} / \mathrm{dL}$ ) and by Rohlfing et al. (35 $\mathrm{mg} / \mathrm{dL})[10,14]$. The latter authors calculated the mean glucose levels of 1,439 patients with type 1 diabetes enrolled in the DCCT by measuring glucose levels seven times daily using a capillary test (before and after meals, and at bedtime). In that study, the Pearson correlation coefficient $(r)$ was 0.82 , and the change in mean glucose level per $1 \%$ increase in HbAic level was $35.6 \mathrm{mg} / \mathrm{dL}$. The 


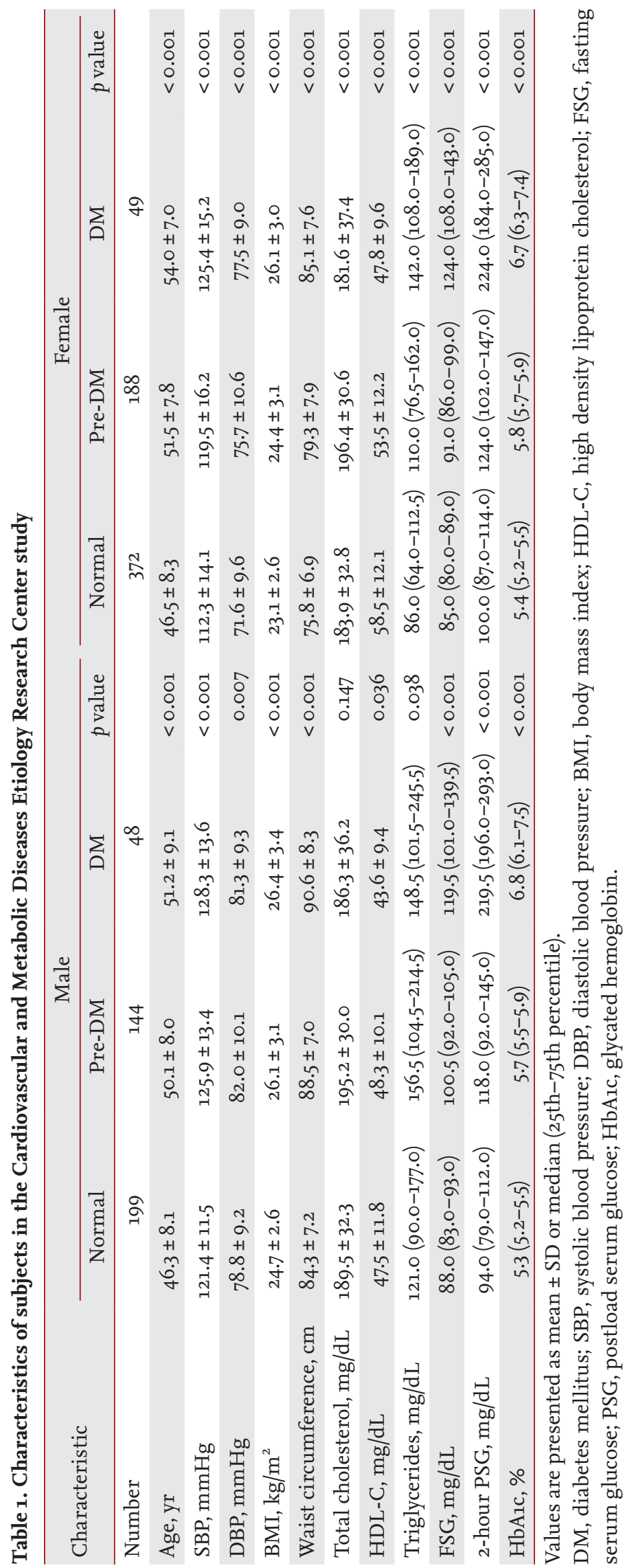

ADA accepted these figures as evidence of a relationship between the HbAic and mean glucose levels. Nathan et al. [10], reporting on the ADAG study group, noted that a prior international multicenter study included a relatively small cohort of patients including both type 1 and type 2 diabetes patients and non-diabetic volunteers. The correlation between the HbArc and the calculated mean blood glucose levels during the prior 3 months was stronger than that observed in the present study $\left(R^{2}\right.$ $=0.84$ compared with our value of $R^{2}=0.54$ ).

Thus, our correlation coefficient was considerably lower than those of the DCCT cohort and ADAG studies. Our OGTT data were derived from single measures of post-loading glucose level, predominantly recorded in the morning. The DCCT cohort study collected seven-point profiles, and glucose was measured before and after every meal, and at bedtime. Interestingly, in the DCCT cohort, the bedtime, post-lunch and post-dinner blood glucose levels were more strongly correlated with HbArc levels than were fasting and post-breakfast levels. The type of diabetes studied may also affect the results. In Pima Indians with type 2 diabetes, the correlations of $\mathrm{HbA1c}$ levels with fasting and post-loading glucose levels during the OGTT were lower (the Pearson correlation coefficient [r], o.6 to 0.7) [15]. However, in the ADAG study, no difference by subgroup of diabetes type was evident.

Differences in average glucose levels reflect the different testing methods used. Specifically, whereas the ADAG study analyzed data obtained via continuous glucose monitoring (CGM, every 5 minutes) and self monitoring blood glucose (SMBG) performed seven times per day (i.e., before and after each meal, and before bed) for 3 months, most of our data came from the OGTT. Besides, the differences in mean blood glucose levels could be affected by a fundamental gap between capillary blood glucose and serum glucose value.

Goldstein et al. [16] addressed the common misconception that, because the $\mathrm{HbAic}$ level reflects the mean level of glycemia during the prior several months, large changes in glycemia cannot be detected for many weeks. A large change in average glucose level is accompanied by a large change in $\mathrm{HbA1c}$ level within 1 to 2 weeks, not 3 to 4 months. The average glucose level over the 30 days immediately preceding blood sampling contributes $\sim 50 \%$ to the final result, and the level over days 90 to 120 
Table 2. Distribution of serum glucose (mg/dL) levels by HbA1c levels

\begin{tabular}{|c|c|c|c|c|c|c|c|c|c|c|c|c|}
\hline \multirow{3}{*}{ Variable } & \multicolumn{12}{|c|}{ Serum glucose, mg/dL } \\
\hline & \multicolumn{6}{|c|}{ Male } & \multicolumn{6}{|c|}{ Female } \\
\hline & No. & Fasting & $30 \mathrm{~min}$ & $60 \mathrm{~min}$ & $120 \mathrm{~min}$ & Mean $^{a}$ & No. & Fasting & $30 \mathrm{~min}$ & $60 \mathrm{~min}$ & $120 \mathrm{~min}$ & Mean $^{\mathrm{a}}$ \\
\hline \multicolumn{13}{|l|}{ HbAic, \% } \\
\hline $4.0-4 \cdot 9$ & 14 & 84.9 & 129.9 & 127.2 & 96.4 & 109.6 & 27 & 81.3 & 122.1 & 108.8 & $95 \cdot 7$ & 102.0 \\
\hline $5 \cdot 0-5 \cdot 6$ & 238 & 90.9 & 151.2 & 140.3 & 101.0 & 120.8 & 381 & 85.8 & 133.5 & 120.0 & 105.8 & 111.3 \\
\hline $5.7-6.4$ & 109 & 98.6 & 166.7 & 180.2 & 129.2 & 143.7 & 167 & $93 \cdot 9$ & 160.2 & 160.0 & $125 \cdot 9$ & $135 \cdot 0$ \\
\hline $6.5-6.9$ & 10 & 123.9 & 206.6 & 250.8 & 187.6 & 192.2 & 14 & 120.4 & 198.8 & 242.6 & $189 \cdot 3$ & 187.8 \\
\hline $7 \cdot 0-7 \cdot 9$ & 11 & 129.1 & 232.6 & $289 \cdot 4$ & 266.3 & $229 \cdot 3$ & 12 & 140.3 & 241.3 & 276.2 & 254.0 & 228.0 \\
\hline $8.0-8.9$ & 4 & $143 \cdot 3$ & $244 \cdot 3$ & 312.0 & 310.8 & 252.6 & 4 & 146.0 & 246.3 & $317 \cdot 5$ & $317 \cdot 5$ & 256.8 \\
\hline $9.0-9.9$ & 2 & 152.0 & 236.5 & 333.5 & 366.5 & 272.1 & 2 & 240.0 & 334.5 & 415.0 & 432.0 & $355 \cdot 4$ \\
\hline$>10$ & 3 & 168.3 & 282.7 & 376.0 & 351.7 & 294.7 & 2 & 265.0 & 382.5 & 481.0 & 446.5 & 393.8 \\
\hline
\end{tabular}

HbAic, glycated hemoglobin.

${ }^{\mathrm{a}}$ Mean values were calculated from the average fasting, 30-minute, 60-minute, and 2-hour serum glucose levels.

Table 3. Comparison of eAG levels by HbAic levels

\begin{tabular}{|c|c|c|c|}
\hline \multirow{2}{*}{ Variable } & \multicolumn{3}{|c|}{ eAG, mg/dL } \\
\hline & CMERC $^{\mathrm{a}}$ & Rohlfing et al. (2002) ${ }^{b}[14]$ & $\operatorname{ADAG}(2008)^{\mathrm{c}, \mathrm{d}}[10]$ \\
\hline \multicolumn{4}{|l|}{ HbAic, \% } \\
\hline 5 & $97 \cdot 4$ & - & $97(76-120)$ \\
\hline 6 & 146.8 & 135 & $126(100-152)$ \\
\hline 7 & 196.2 & 170 & $154(123-185)$ \\
\hline 8 & 245.6 & 205 & $183(147-217)$ \\
\hline 9 & 295 & 240 & $212(170-249)$ \\
\hline 10 & $344 \cdot 4$ & 275 & $240(193-282)$ \\
\hline 11 & 393.8 & 310 & $269(217-314)$ \\
\hline 12 & 443.2 & 345 & $298(240-347)$ \\
\hline
\end{tabular}

eAG, estimated average glucose; HbA1c, glycated hemoglobin; CMERC, Cardiovascular and Metabolic Diseases Etiology Research Center; ADAG, Alc-Derived Average Glucose.

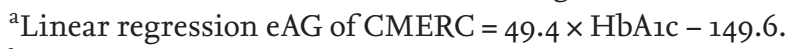

${ }^{\mathrm{b}}$ Linear regression eAG of Rohlfing et al. $=35.6 \times \mathrm{HbAic}-77.3$.

${ }^{\mathrm{c}}$ Linear regression eAG of ADAG $=28.7 \times \mathrm{HbA1c}-46.7$.

${ }^{\mathrm{d}}$ Data in parentheses are $95 \%$ confidence intervals.

prior contributes only $\sim 10 \%$. The difference in eAG level between the DCCT and ADAG study is explained by differences in the frequency of glucose measurements; the DCCT featured a seven-point profile only, whereas CGM and seven-point profiling captured a median of 52 days of data in the ADAG [10].

However, differences in glycemic control capacity between Caucasian and Korean populations may also have influenced our results. Reduced insulin secretion, rath- er than insulin resistance, has long been considered the major pathogenic defect in type 2 diabetes patients in Korea; the Korean population is less obese than Western populations are [17]. Thus, in Koreans with impaired glucose tolerance or type 2 diabetes, reduced insulin secretion can trigger hyperglycemia during the OGTT, increasing the mean blood glucose level, which could explain the difference between the results of the present study and those of the ADAG. The average blood glucose 
was $154 \mathrm{mg} / \mathrm{dL}$ (95\% confidence interval, 123 to 185 ) in patients with $\mathrm{HbA1c}$ of $7 \%$ in the ADAG study. In the present study, the mean values of mean and peak blood glucose levels during the OGTT were 196 and 240 to 250 $\mathrm{mg} / \mathrm{dL}$ at that HbAic level. Thus, a major difference between the groups is evident. Although no variation in terms of ethnicity is evident in the ADAG data, too few Asians were included to allow a conclusion that Asians are similar to Caucasians in terms of the relationship between the HbAic and mean glucose levels.

The principal limitation of the present study is that we performed the OGTT only once. In subjects with normal glucose tolerance, the average blood glucose may vary over 3 months, and a single mean blood glucose level derived using the OGTT is not representative of the values of the previous 3 months. This may have made our correlation coefficient lower than those of other studies. Of our 1,000 study participants, only 97 had been previously diagnosed or were newly diagnosed with diabetes. Of the nine diabetic patients with $\mathrm{HbArc}$ values $\geq 8 \%$, only three had values $\geq 10 \%$, which may have compromised the accuracy of the equation derived. And, we didn't take blood samples at 90 minutes. So, we estimated the 90 minutes blood glucose level by obtaining average of 60 and 120 minutes glucose level, and estimated mean blood glucose was slightly higher than the value reported by our study. But it didn't show significant difference.

Carbohydrate-rich diets are common in Korea. No prior study has evaluated the association between mean blood glucose level during OGTT and SMBG results. However, theoretically, the relationship between mean blood glucose levels and HbArc levels may differ when the OGTT rather than SMBG is used.

In our present study of 1,000 members of the CMERC cohort, an association between HbA1c and mean blood glucose level was apparent. In comparison with studies performed in other countries that measured glucose levels continuously or that analyzed SMBG values, the mean glucose levels observed in the present study were higher for each chosen HbAic value. These discrepancies may be attributable to the different test methods used and physiological characteristics unique to Koreans. More studies seeking to identify associations between HbA1c and mean blood glucose level using CGM or SMBG over long periods are needed.

\section{KEY MESSAGE}

1. In our present study of 1,000 members of the Cardiovascular and Metabolic Diseases Etiology Research Center cohort, an association between glycated hemoglobin (HbAic) and mean blood glucose level was apparent.

2. The estimated linear regression equation is mean glucose $(\mathrm{mg} / \mathrm{dL})=49.4 \times \mathrm{HbAlc}(\%)-149.6$ $\left(R^{2}=0.54, p<0.001\right)$.

3. Our liner regression equation was quite different from that of the Alc Derived Average Glucose study and Diabetes Control and Complications Trial cohort.

\section{Conflict of interest}

No potential conflict of interest relevant to this article is reported.

\section{Acknowledgments}

This study was supported by a grant from the Korean Health Technology R\&D Project, Ministry of Health and Welfare, Korea (No. HI13Co715).

\section{REFERENCES}

1. Jeon JY, Kim DJ, Ko SH, et al. Current status of glycemic control of patients with diabetes in Korea: the fifth Korea national health and nutrition examination survey. Diabetes Metab J 2014;38:197-203.

2. Harris MI, Klein R, Welborn TA, Knuiman MW. Onset of NIDDM occurs at least 4-7 yr before clinical diagnosis. Diabetes Care 1992;15:815-819.

3. International Expert Committee. International Expert Committee report on the role of the $\mathrm{AlC}$ assay in the diagnosis of diabetes. Diabetes Care 2009;32:1327-1334.

4. American Diabetes Association. Diagnosis and classification of diabetes mellitus. Diabetes Care 2010;33 Suppl 1:S62-S69.

5. Saudek CD, Herman WH, Sacks DB, Bergenstal RM, Edelman D, Davidson MB. A new look at screening and diagnosing diabetes mellitus. J Clin Endocrinol Metab 2008;93:2447-2453.

6. The Diabetes Control and Complications Trial Research Group. The effect of intensive treatment of diabetes on 
the development and progression of long-term complications in insulin-dependent diabetes mellitus. N Engl J Med 1993;329:977-986.

7. Stratton IM, Adler AI, Neil HA, et al. Association of glycaemia with macrovascular and microvascular complications of type 2 diabetes (UKPDS 35): prospective observational study. BMJ 2000;321:405-412.

8. Control Group, Turnbull FM, Abraira C, et al. Intensive glucose control and macrovascular outcomes in type 2 diabetes. Diabetologia 2009;52:2288-2298.

9. Beard E, Clark M, Hurel S, Cooke D. Do people with diabetes understand their clinical marker of long-term glycemic control (HbAic levels) and does this predict diabetes self-care behaviours and HbArc? Patient Educ Couns 2010;80:227-232.

10. Nathan DM, Kuenen J, Borg R, et al. Translating the AlC assay into estimated average glucose values. Diabetes Care 2008;31:1473-1478.

11. Makris K, Spanou L. Is there a relationship between mean blood glucose and glycated hemoglobin? J Diabetes Sci Technol 2011;5:1572-1583.
12. Del Prato S. Loss of early insulin secretion leads to postprandial hyperglycaemia. Diabetologia 2003;46 Suppl 1:M2-M8.

13. Monnier L, Lapinski H, Colette C. Contributions of fasting and postprandial plasma glucose increments to the overall diurnal hyperglycemia of type 2 diabetic patients: variations with increasing levels of $\mathrm{HbA}(1 \mathrm{c})$. Diabetes Care 2003;26:881-885.

14. Rohlfing CL, Wiedmeyer HM, Little RR, England JD, Tennill A, Goldstein DE. Defining the relationship between plasma glucose and $\mathrm{HbA}(1 \mathrm{c})$ : analysis of glucose profiles and $\mathrm{HbA}(1 \mathrm{c})$ in the Diabetes Control and Complications Trial. Diabetes Care 2002;25:275-278.

15. American Diabetes Association. Postprandial blood glucose. Diabetes Care 2001;24:775-778.

16. Goldstein DE, Little RR, Lorenz RA, et al. Tests of glycemia in diabetes. Diabetes Care 2004;27:1761-1773.

17. Yoon $\mathrm{KH}$, Ko SH, Cho JH, et al. Selective beta-cell loss and alpha-cell expansion in patients with type 2 diabetes mellitus in Korea. J Clin Endocrinol Metab 2003;88:23002308. 